
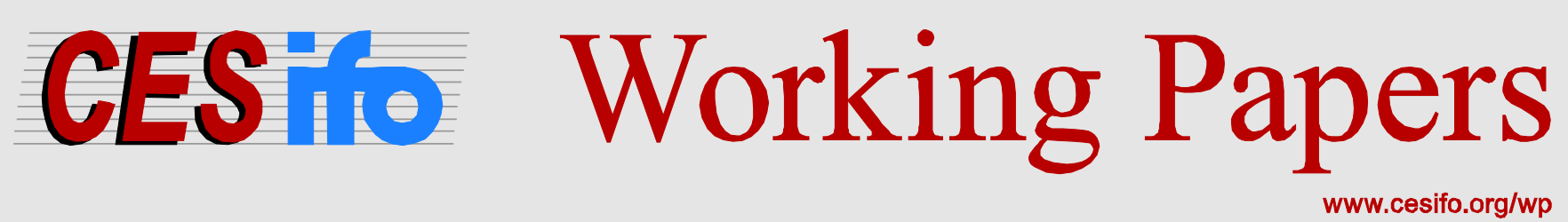

\title{
Do Minimum Legal Tobacco Purchase Age Laws Work?
}

\author{
Ceren Ertan Yörük \\ Barış K. Yörük
}

CESIFO WORKING PAPER NO. 4860

CATEGORY 1: PUBLIC FinANCE

JUNE 2014

An electronic version of the paper may be downloaded

- from the SSRN website:

- from the RePEc website:

- from the CESifo website:

wWw.SSRN.com

www.RePEc.org

www.CESifo-group.org/wp

\section{CESifo}




\title{
Do Minimum Legal Tobacco Purchase Age Laws Work?
}

\begin{abstract}
This paper uses a regression discontinuity design to estimate the impact of the minimum legal tobacco purchase age (MLTPA) laws on smoking behavior among young adults. Using data from the confidential version of National Longitudinal Survey of Youth (1997 Cohort), which contains information on the exact birth date of the respondents, we find that the impact of the MLTPA on several indicators of smoking among youth is minor and often insignificant. However, we also show that granting legal access to cigarettes and tobacco products at the MLTPA leads to an increase in several indicators of smoking participation, including up to a 5 percentage point increase in the probability of smoking for males and for those who reported to have smoked before. These results are robust under several alternative model specifications and imply that policies that are designed to restrict youth access to tobacco are only effective in reducing smoking participation among certain groups of young adults.
\end{abstract}

JEL-Code: I100, I180, I190.

Keywords: minimum legal tobacco purchase age, smoking.

\author{
Ceren Ertan Yörük \\ Sage Colleges \\ 140 New Scotland Ave. \\ USA - Albany, NY 12208 \\ yorukc@sage.edu
}

\author{
Barış K. Yörük \\ University at Albany, SUNY \\ 1400 Washington Ave. \\ USA - Albany, NY 12222 \\ byoruk@albany.edu
}

June 12, 2014

This paper uses confidential data provided by Bureau of Labor Statistics (BLS). The views expressed in this paper are those of the authors and do not necessarily reflect those of the BLS. The authors thank the session participants of SEA conference (2013) and Daniel Rees for helpful comments. 


\section{Introduction}

Smoking is identified as a major cause of wide variety of health problems such as heart disease, stroke, and several different forms of cancer. U.S. Surgeon General's report (2004) states that damage from tobacco smoke is immediate and smoking harms nearly every major organ of the body, often in profound ways, causing many diseases and significantly diminishing the health of smokers in general. Furthermore, compared with nonsmokers, smokers are more prone to illness and more likely to reach exhaustion. Empirical literature also documents that smoking has a significant impact on other health related outcomes such as mental illness or obesity. ${ }^{1}$ Through its depressant effects on health, smoking might also have substantive negative spillover effects on economic outcomes, including several labor market outcomes such as income, productivity, and wages. ${ }^{2}$ Given these direct and indirect effects of smoking, evaluating the effectiveness of the policies that are used to regulate smoking behavior is vital.

Several recent studies have documented that policies that increase the cost of smoking such as raising taxes on cigarettes and tobacco products and imposing public smoking bans significantly reduce smoking participation and may have positive spillover effects on smoking related outcomes. For instance, DeCicca and McLeod (2008) find that higher taxes reduce smoking participation by older adults, especially those who are less educated and live in low-income households. Carpenter and Cook (2008) show that tobacco tax increases are associated with significant reductions in smoking participation and frequent smoking by youths. Using rich longitudinal data from the German SocioEconomic Panel Study, Anger, Kvasnicka, and Siedler (2011) investigate the impact of public smoking bans on smoking behavior. They find that individuals who go out more often to bars and restaurants adjust their smoking behavior as a response to a public smoking ban and as a result, they become less likely to smoke and also smoke less. On the other hand, Carpenter, Postolek, and Warman (2011) find that public-place smoking laws are effective tools at reducing non-smokers' and smokers' exposure to environmental tobacco smoke in a variety of public places on a broad, population-wide scale.

According to the Substance Abuse and Mental Health Services Administration of the U.S. Department of Health and Human Services, almost 90 percent of cigarette smokers started at or before age

\footnotetext{
${ }^{1}$ For example, Gruber and Frakes (2006), Courtemanche (2009), Baum (2009), and Liu et al. (2010) document the relationship between smoking and obesity.

${ }^{2}$ Leigh and Berger (1989), Levine, Gustafson, and Velenchik (1997), and Auld (2005) show that smoking is negatively associated with labor matket outcomes.
} 
18. As a natural consequence, one of the most direct forms of regulation on smoking behavior in the United States is imposing a minimum legal cigarette and tobacco products purchase age (hereafter, MLTPA). Although MLTPA is 18 in most states, there are few states and counties that impose a higher MLTPA. Understanding the effect of the MLTPA is particularly important not only because smoking has been linked to several undesirable health and economic outcomes, but also increasing the MLTPA from 18 to 19 or 21 is a current policy debate in many states. Proponents of a higher MLTPA argue that increasing the legal age for tobacco sales will make it difficult for younger teens, such as 16-year-olds, to get cigarettes since younger teens typically know a lot more 18-year-olds than 21-year-olds who might buy them cigarettes. However, opponents of a higher MLTPA argue that there is no sufficient evidence to support that raising the age for being able to buy tobacco products has any real effect on keeping young adults away from tobacco products.

Although several studies have investigated the effect of the MLTPA laws on smoking habits of young adults, most of them have made use of the changes in the MLTPA laws that occurred in the 1980s and early 1990s at the state level. However, states where a MLTPA of 18 was imposed might be different in unobserved ways than those states where a higher MLTPA was enforced. If these unobserved differences at the state level are also associated with smoking habits of young adults, then one cannot estimate a consistent effect of the MLTPA on cigarette consumption and smoking related outcomes using the simple variation of the MLTPA law at the state level. In order to address this shortcoming, we exploit the discontinuity in smoking habits of young adults at the MLTPA and use a regression discontinuity (hereafter, RD) design to estimate the causal effect of the MLTPA on several indicators of smoking participation. Our main identifying assumption is that the observed and unobserved determinants of smoking related outcomes are likely to be distributed smoothly across the MLTPA. ${ }^{3}$ Hence, any possible change in smoking habits and smoking related outcomes at the MLTPA can solely be attributed to the MLTPA law itself.

We use a restricted version of the National Longitudinal Survey of Youth, 1997 Cohort (NLSY97) for the empirical analysis. This restricted version contains unique information on the exact birth date of the respondents as well as their county and state of residence, which is quite important in the context of a RD design. ${ }^{4}$ Since the MLTPA laws differ at the county and state level and are

\footnotetext{
${ }^{3}$ This is a partially testable assumption. Relevant tests are presented in section 5 .

${ }^{4}$ MLTPA may differ at the state and county level. Therefore, the information on state and county of residence is crucial to identify the treatment and control groups. The information on the exact birthdate of each respondent is also
} 
imposed based on a simple age cut-off, this information enables one to clearly identify the treatment and control groups and compare the smoking habits of youths who are slightly younger than MLTPA with those who are slightly older than this cut-off age.

To our best knowledge, this is the first study to investigate the impact of the MLTPA laws at the national level using a RD design. We also investigate the effects of the MLTPA on young adults who belong to different demographic groups or who are subject to different MLTPAs such as 18 and 19. Our results suggest that the overall effect of the MLTPA on several indicators of smoking among youth is minor and often insignificant. However, we also find that granting legal access to cigarettes and tobacco products at the MLTPA leads to an increase in several indicators of smoking for males and for those who reported to have smoked before. In particular, we find that for those who reported to have smoked before, the MLTPA is associated with up to a 5 percentage point increase in the probability of smoking in the past month, a 25 percent increase in the number of days that they smoke cigarettes per month, and a 9.5 percent increase in the number of cigarettes that they smoke on the days they actually smoke. These results are robust under alternative parametric and non-parametric model specifications.

The rest of this paper is organized as follows. The next section provides background information on the MLTPA laws and discusses the relevant research. Section 3 presents the data and empirical methodology and discusses the relationship between the MLTPA and smoking. Section 4 presents the results and discusses the sensitivity of main findings under alternative models and for youths who belong to different demographic groups. Section 5 provides a discussion of policy implications and concludes.

\section{Background and literature review}

Since April 1, 1988, the sale of cigarettes and other tobacco products to people under the state purchase age has been prohibited by law in all states of the United States. Any state may set the

crucial. Suppose that a respondent resides in a state that enforces a MLTPA of 18. Furthermore, suppose that one has information only on the month and year of the birthdate of this respondent. If this respondent was born on January 30 , 1980 and interviewed on January 1, 1998, he will be mistakenly coded as a 18 year old and included in the treatment group (those who are 18 and older). But, this respondent is actually in the control group since she is 29 days younger than 18 at the time of the interview date. Furthermore, by definition, the RD approach estimates the local treatment effect, which calls for a very detailed information around the MLTPA cut-off. 
purchasing age limit lower than 18 years but this would result in the loss of grants from the Federal Emergency Management Agency that otherwise would be given for a natural disaster in that state. In general, almost all states in the United States adopted 18 years as the MLTPA. There are few exceptions, however. Alabama, Alaska, and Utah increased their MLTPA from 18 to 19 in 1997 and have enforced the same age limit since then. Suffolk county in New York increased the MLTPA from 18 to 19 in 2005. New Jersey and Nassau county in New York have increased their MLTPA from 18 to 19 in 2006. Onondaga county in New York has increased the MLTPA to 19 in 2009. Pennsylvania prohibited teens under the age of 21 from buying cigarettes and tobacco products until July 10, 2002 but since then, it enforces a lower MLTPA of 18.

Empirical evidence on the effectiveness of the youth access laws on smoking is mixed. Chaloupka and Grossman (1996) and DeCicca, Kenkel, and Mathios (2002) find little impact of access restrictions and higher taxes on youth smoking, while Gruber and Zinman (2001) and Chalupka and Pacula (1998) argue that such restrictions lower the quantity of cigarettes smoked by younger smokers. Chaloupka and Pacula (1998) focus on youth access restriction enforcement and find that more tightly enforced youth access restrictions lower youth smoking. Their estimates suggest that when the limits on youth access are comprehensively and aggressively enforced and highly complied with, they significantly reduce the prevalence of youth smoking. Using data from the 1992 and 1993 waves of the Current Population Survey, Hersch (1998) argues that unlike higher cigarette taxes, age-related smoking restrictions have little effect on teen smoking. Recently, in a dynamic simulation model, Ahmad and Billimek (2007) find that comparable to a large tax-induced price increase, raising MLTPA to 21 would have a minimal immediate effect on adult smoking prevalence and population health, but would cause almost a $13 \%$ drop in smoking prevalence for 15 to 17 year-olds. Using data from Monitoring the Future Survey, DiFranza, Savageau, and Fletcher (2009) find that improving merchant compliance with the prohibition on sales of tobacco to minors and increasing the price of cigarettes discourage youth smoking.

Past studies that investigate the effect of the MLTPA laws on smoking have two major limitations. First, most of these studies cover data from late 1980s and early 1990s. However, the youth access laws are widely perceived to have been ineffective during this time period due to lack of enforcement (DeCicca et al., 2008). Second, most of the earlier studies used the state level variation in the MLTPA laws to identify the effect of these laws on smoking behavior. However, states where a lower MLTPA 
was imposed might be different in unobserved ways than those states where the MLTPA of 19 or 21 was enforced. If these unobserved differences at the state level are also correlated with the smoking habits of young adults, then one cannot estimate a consistent effect of the MLTPA laws on smoking and smoking related outcomes using the simple variation of the MLTPA law at the state level. The $\mathrm{RD}$ approach used in this paper alleviates this shortcoming by removing the bias from unobserved policy preferences. Our empirical approach is similar to that of Yan (2011) who employs a RD design to investigate the effect of the MLTPA of 21 at Pennsylvania on smoking behavior of young mothers. He finds that the MLTPA at Pennsylvania is associated with a 16 percent increase in the average number of cigarettes smoked per day among young mothers. He also shows that for smoking mothers, having legal access to cigarette just before the end of the first trimester would lower an infant's birth weight by 60 grams. However, our study differs from that of Yan (2011) in several ways. First, instead of focusing on a single state, we investigate the impact of the MLTPA laws at the national level. Second, we employ a different individual level survey (NLSY97) that contains information on the exact birth day and state and county of residence of the respondents. This data set has also the advantage of containing a more comprehensive range of smoking outcomes than previous research.

\section{Data and empirical methodology}

We use data from the NLSY97 for the empirical analysis. The NLSY97 consists of a nationally representative sample of 9022 youths who were 12 to 16 years old as of December 31, 1996. Round 1 of the survey took place in 1997. In that round, both the eligible youth and one of that youth's parents received hour-long personal interviews. Youths continue to be interviewed on an annual basis. In addition to standard demographic information, the survey respondents were also asked detailed questions about their smoking habits. Our outcome variables are derived from these questions. We present the description of these variables and their summary statistics in Table 1 for the full sample, for those who are younger or older than the MLTPA, and for those who smoked at least once since the date of their last interview (DLI). ${ }^{5}$

A unique feature of our data set is that we have obtained access to a confidential version of the

\footnotetext{
${ }^{5}$ In Table 1, we report the sample weighted means for outcome variables. However, we do not use sample weights in our regressions. Although not reported, sample weighted regressions yield comparable estimates. These results are available upon request.
} 
NLSY97 with information on respondents' state and county of residence, exact date of birth, and exact interview date for each survey year. We use this information to determine the MLTPA for each county and state and to calculate the exact age in days for each respondent at the time of the interview. Therefore, for each respondent, we were able to determine the MLTPA that she is subject to and the number of days that she is younger or older than the MLTPA. We restrict our sample to those respondents who were surveyed over the period 1998-2004, were up to 2 years younger or older than the MLTPA, and were single as of the interview date. ${ }^{6}$ As in similar surveys of its kind, the respondents of the NLSY97 who reported to have smoked at least once since the DLI were also asked about their smoking habits over the past month. ${ }^{7}$ This relatively short reference period is desirable since our empirical strategy compares those who are slightly older than the MLTPA with those who are slightly younger than this cutoff age. In order investigate the impact of the MLTPA on smoking behavior, we consider four main smoking outcomes. These variables are whether the respondent smoked over the past month, number of days that she smoked over the past month, number of cigarettes that she smoked on the days she actually smoked, and the average number of cigarettes that she smoked per day over the past month. ${ }^{8}$

We use a RD design to estimate effect of the MLTPA laws on smoking and smoking related

\footnotetext{
${ }^{6}$ Our choice of age bandwidth follows Carpenter and Dobkin (2009) and Yörük and Ertan Yörük (2011 and 2013 ). However, under alternative age bandwidths such as 1 year or 1.5 years, the effect of the MLTPA on smoking remains insignificant. The majority of states in the United States requires that a couple be 18 in order to marry without parental permission. Marital status may significantly affect smoking behavior of youths. Given that the MLTPA in most states is 18 as well, including married youths to our sample may cause an identification problem. Therefore, in this paper, we focus on single youths only. Accordingly, we dropped 532 observations, who reported being married as of the interview date.

${ }^{7}$ For instance, in National Health Interview Survey (NHIS) and National Youth Tobacco Survey (NYTS), questions on smoking habits typically refer to the prior month. However, NHIS may not be appropriate to test the spillover effects of the MLTPA on alcohol consumption since questions on alcohol consumption in the NHIS typically refer to the prior 12 months with an option to report alcohol consumption over the past year, the past month, or the past week. On the other hand, NYTS does not provide information on the exact birth date of the respondent and therefore, is not suitable for our empirical strategy.

${ }^{8}$ We do not directly observe the binary variable that measures whether the respondent smoked over the past month. For those respondents who never smoked or did not smoke since the DLI, this binary variable is equal to zero. The respondents who reported smoking at least once since the DLI were asked the following question: "During the past 30 days, on how many days did you smoke a cigarette?" The smoking participation variable for the corresponding question is coded unity if the respondent reported smoking on at least one day during the past month and zero otherwise. The respondents were also asked the following question: "When you smoked a cigarette during the past 30 days, how many cigarettes did you usually smoke each day?" In order to calculate the average number of cigarettes that the respondent smoked per day over the past month, we multiply the number of days that the respondent smoked over the past month with the number of cigarettes that she smoked on those days and divide the result by 30 .
} 
outcomes among young adults. ${ }^{9}$ This approach exploits the sudden change in smoking habits that may occur at the MLTPA. Since purchase of tobacco products are legally allowed according to a simple age cutoff, we are able to compare outcomes across youths with similar income and other observable individual characteristics, but with very different smoking habits. The main RD model used in our empirical analysis is as follows:

$$
Y_{i t}=\beta^{\prime} X_{i t}+\gamma T_{i t}+g\left(A_{i t}\right)+\eta_{t}+\mu_{i}+\varepsilon_{i t}
$$

where $Y_{i t}$ represents a particular smoking outcome for individual $i$ at time $t$. The vector of time dependent observable characteristics for individual $i$ are denoted by $X_{i t}$ and includes dummy variables controlling for household income, student and employment status of the respondent, and a dummy variable which controls for the birthday celebration effect and equals to one if the respondent was interviewed during the first month after turning the MLTPA. ${ }^{10}$ In general, these control variables vary smoothly around the MLTPA. Hence, they have little effect on our estimates of the discontinuity and serve mainly to increase the precision of our estimates. Since our data contain information on some youths at more than one time period, in our empirical analysis, we control for time invariant individual characteristics $\left(\mu_{i}\right)$ and fixed year effects $\left(\eta_{t}\right)$ and report the standard errors that are clustered at the individual level. ${ }^{11}$ The treatment variable is denoted by $T_{i t}$ and takes the value of unity if the respondent's age is greater than or equal to the MLTPA or alternatively, if she is legally allowed to purchase tobacco products as of the interview date and zero otherwise. Since we consider 1998-2004 period, the MLTPA is 19 for those who reside in Alabama, Alaska, and Utah, 21 for those who reside in Pennsylvania and were interviewed before July 10, 2002, and 18 for the rest of the respondents. The coefficient $\gamma$, our main coefficient of interest, indicates the impact of the MLTPA

\footnotetext{
${ }^{9}$ Imbens and Lemieux (2008), Porter (2003), and Lee and Lemieux (2009) present a detailed discussion of the RD design.

${ }^{10}$ Since several observations are missing for household income and employment status, we use dummy variables controlling for the "missing" observations for these set of covariates. Following Carpenter and Dobkin (2009), the birthday celebration effect dummy controls for the possibility that young adults may simply change their smoking behavior during the first few days following their birthday. Furthermore, outcome variables refer to a one month period. Therefore, those who were interviewed during the first month after turning the MLTPA may be mistakenly placed in the treatment group. The birthday celebration effect dummy controls for this possibility as well. We also estimate models using state fixed effects as additional controls. Although not reported here, compared with our results, these models produce a similar effect of the MLTPA on outcome variables.

${ }^{11}$ Some of the time invariant individual characteristics such as gender and race are observed. In our empirical model, these variables are captured by the individual fixed effects. Figure 1 shows that these variables are distributed smoothly around the MLTPA.
} 
law on the relevant outcome variable. Finally, $g\left(A_{i t}\right)$ is a smooth function of age profile, which is also known as the forcing variable in the context of a RD design. ${ }^{12}$ Since, we observe the state of residence, and exact birth and interview date for each respondent, we were able to calculate the difference between the interview date and the MLTPA. Therefore, for each respondent, the variable $A_{i t}$ represents the number of days before or after the MLTPA.

Modelling the smooth function of age profile correctly is one of the main problems in implementing the RD design. Our most general parametric model with a quadratic polynomial of age that is fully interacted with the treatment variable can be written as:

$$
Y_{i t}=\beta^{\prime} X_{i t}+\gamma T_{i}+\sum_{j=1}^{k=2} \alpha_{j} A_{i t}^{j}+\sum_{j=1}^{k=2} \lambda_{j}\left(T_{i t} \times A_{i t}^{j}\right)+\eta_{t}+\mu_{i}+\varepsilon_{i t} .
$$

We test the sensitivity of our parametric models to a variety of functional form assumptions. In particular, we focus on linear and quadratic models, allowing the slope of these functions to vary on each side of the age cutoff. (i.e., linear and quadratic splines). We also estimate models with and without interaction terms and for alternative subsamples of respondents.

In order to test whether our results are robust to model specification, we also estimate nonparametric RD models. In these models, following Hahn, Todd, and van der Klaauw (2001) and Porter (2003), we use local linear regressions to estimate the left and right limits of discontinuity at the MLTPA. The difference between the two limits is the local treatment effect of the MLTPA law on outcome variables. Following Malamud and Pop-Eleches (2011), we estimate this in one step using triangular kernel which has been shown to be boundary optimal by putting more weight on observations closer to the cutoff point (Cheng, Fan, Marron, 1997). The remaining estimation issue for non-parametric models is the selection of appropriate bandwidth. Since the RD is identified only at the discontinuity, one has to balance the goals of staying as local to the cutoff point at the MLTPA as possible while ensuring that there exists enough data to yield informative estimates. Although there is currently no widely agreed-upon method for selection of optimal bandwidths in the nonparametric RD context, we follow a new method proposed by Imbens and Kalyanaraman (2012). For non-parametric models, we calculate the standard errors using the bootstrap procedure with 1000 replications. This approach may offer more accurate asymptotic inference than the analytic standard errors (Cameron and Trivedi, 2005).

\footnotetext{
${ }^{12}$ In order to implement the RD design, we assume that the respondents do not have any control over the forcing variable. Since our forcing variable is age, this condition is naturally satisfied.
} 


\section{Results}

This section reports the results from several parametric and non-parametric RD models estimated for different smoking outcomes. In the United States, 18 is the age of majority, which is also the MLTPA in most states. In addition to a right to purchase cigarettes and tobacco products, young adults gain several other rights at this age. If these rights are correlated with smoking behavior among young adults, then failure to control for them may bias the estimated impact of the MLTPA laws on smoking and smoking related outcomes. It is plausible to argue that most of the rights gained at age 18 such as rights to vote, to make a will, to sign a contract, and to apply for a credit are uncorrelated with smoking habits. However, at age 18, young adults also gain rights that will allow them to be independent from parental control and therefore, they may move out from their parents' house or may start to work instead of pursuing college education. These changes may significantly affect smoking habits. In order to address this problem, we test the possibility that there exists other significant changes in observable characteristics of young adults occurring at the MLTPA that could confound our analysis. For instance, if young adults leave their parents' house or start to work at the MLTPA, then their observable characteristics such as employment status and household income should exhibit a discrete change at the MLTPA. We estimate equation (2) separately for each observable covariate using a quadratic spline. ${ }^{13}$ The results reported in Table 2 suggests that for each covariate, the coefficient of the treatment variable is insignificant and hence, observable characteristics of young adults are orthogonal to the age variable and there is no evidence of significant discontinuous change in any of these variables at the MLTPA. ${ }^{14}$ We also graph the corresponding age profiles of selected covariates in Figure 1. The quadratic prediction of each variable appears to fit the actual data well and exhibits either no or an insignificant small jump at the MLTPA. Although, we cannot directly test whether the unobservable characteristics of youths vary smoothly across the MLTPA, our finding that observable characteristics are smoothly distributed around the MLTPA reduces the concerns about omitted variables bias and suggests that parametric models estimated with or without controls

\footnotetext{
${ }^{13}$ Following the previous literature, our selection of a quadratic polynomial is a result of a visual inspection of data for the best fit. Estimating this model separately for all control variables using linear or cubic splines yields similar results.

${ }^{14}$ In column 2, we test whether $\ln$ (income) is distributed smoothly around the MLTPA. In empirical models, rather than using a continuous measure of income, we use dummy variables controlling for different income ranges and missing information on income. Models estimated using $\ln$ (income) yields comparable results and available upon request.
} 
should yield similar results. ${ }^{15}$

Another possible concern to identification in a RD design comes from the possibility of nonrandom sorting of young adults to either side of the MLTPA cutoff. Nonrandom sorting of respondents around the MLTPA cutoff might be possible if survey nonresponse is higher among those who are slightly older than the MLTPA because they have moved away from their parents or they are more difficult to survey. However, survey response rate in the NLSY97 is quite high and there is no evidence that nonresponse rate of those who are older than the MLTPA are higher than those who are younger than this cutoff age.

\subsection{The effect of the MLTPA on smoking}

In Table 3, we report the estimates from parametric regressions of the effect of the MLTPA on alternative measures of smoking participation. ${ }^{16}$ These regressions contain a quadratic polynomial of age which is fully interacted with a dummy variable indicating an age greater than or equal to the MLTPA. Standard errors are clustered at the individual level to correct for the non-independence of individual observations over time. The first three columns report the impact of the MLTPA on the probability of smoking in the past month. As expected, results from the model that is estimated without control variables and individual fixed effects are quite similar compared with the model that contain control variables but not individual fixed effects and the model that contain both control variables and individual fixed effects. Under these alternative specifications, the MLTPA is associated with around 1.9 to 2.9 percentage point increase in the probability of smoking. However, this effect is not significant at conventional significance levels except for the second specification, which contains control variables but not the individual fixed effects. In panel A of Figure 2, we superimpose the quadratic fitted lines from the parametric model estimated without any controls (the first specification

\footnotetext{
${ }^{15}$ Since our empirical analysis is based on self-reported survey data, youths who are slightly younger than the MLTPA may be more likely to underreport their smoking behavior since it is illegal to purchase cigarettes for those who are under the MLTPA. This could generate a discrete jump in reported levels of smoking participation at the MLTPA even if there is no true change in actual smoking behavior. If this is the case, then one would expect that those who are younger than the MLTPA should consistently report less smoking than those who are at the MLTPA. Although not reported here, the probability of smoking trends around the birthday for those who are one year younger than the MLTPA are quite similar to those who are at the MLTPA and to those who are one year older than the MLTPA. This finding implies that the empirical results reported in this paper are not subject to underreporting bias.

${ }^{16}$ In addition to time dependent observable characteristics, specifications 2, 5, 8, and 11 of Table 3 also contain controls for time-invariant characteristics such as dummy variables for being female, black, and Hispanic.
} 
in Table 3) over the mean value of the percent of smokers calculated for each 30-day age block. The figure confirms the estimation results and shows a small but statistically insignificant increase in the probability of smoking at the MLTPA.

The next three columns in Table 3 document the relationship between the number of days that young adults smoke per month and the MLTPA. In our regressions, we use the log transformation of this variable as the dependent variable, therefore the coefficient on the treatment shows the percentage change in smoking days due to the effect of the MLTPA law. ${ }^{17}$ The estimated coefficients on the treatment variable suggest that youths tend to increase the number of days that they smoke per month by 8.8 to 12 percent at the MLTPA cutoff. However, this effect is insignificant. Panel B of Figure 2 also shows a small but statistically insignificant jump in the number of days that young adults smoke cigarettes per month at the MLTPA.

Specifications 7 to 9 in Table 3 report the estimated effect of the MLTPA law on the number of cigarettes that young adults smoke on the days they actually smoke. ${ }^{18}$ Under alternative model specifications, although the number of cigarettes smoked increases by 4.6 to 7.7 percent due to the MLTPA, this effect is not statistically significant. Panel $\mathrm{C}$ of Figure 2 also shows a small and insignificant change in the number of cigarettes that young adults smoke on the days they actually smoke at the MLTPA.

The last three columns of Table 3 show that the average number of cigarettes smoked per day increases by 3.7 to 6.5 percent at the MLTPA. However, as for the other smoking outcomes, this effect is not significant at conventional significance levels. Panel D of Figure 2 illustrates this finding and shows that smoking behavior among young adults exhibits similar trends around the MLTPA cutoff.

\subsection{Alternative models}

Results from our most flexible parametric specification imply that the MLTPA is not a significant determinant of smoking behavior among youth. In this section, we test the sensitivity of our findings

\footnotetext{
${ }^{17}$ In this model, the dependent variable is $\ln ($ Smoking days +0.1$)$. We add 0.1 to the outcome variable since some youths do not smoke. Alternative transformations such as adding 0.5 to this variable before taking its log yield similar results.

${ }^{18}$ If the respondent is a non-smoker, this variable is coded as zero. In our regressions, we use the log transformation of this variable as the dependent variable. In particular, in specifications 7-9 of Table 3, the dependent variable is $\ln ($ No. of cigs.+0.1). Therefore, the coefficient on the treatment variable represents the percentage change in the number of cigarettes smoked due to the MLTPA law. Similarly, in the last three columns of Table 3, the dependent variable is $\ln$ (Avg. cigs+0.1).
} 
under alternative model specifications. Table 4 reports the estimated impact of the MLTPA on smoking outcomes under alternative parametric and non-parametric specifications. The effect of the MLTPA on smoking among young adults is significant under parametric models that are estimated using linear polynomial of age and under the model that is estimated using a quadratic polynomial of age but without any interaction terms. In particular, the results from these models imply that the probability of smoking among young adults increases up to 1.7 percentage points at the MLTPA. Similarly, young adults tend to increase the number of days that they smoke cigarettes by up to 9 percent, the number of cigarettes that they smoke on the days they actually smoke by up to 6.2 percent, and the average number of cigarettes that they smoke per day by up to 6.2 percent when they gain legal access to tobacco products.

However, results from the non-parametric RD models reported in Table 4 show that the MLTPA is not a significant determinant of smoking behavior among young adults. This finding is in line with the results from the most flexible parametric models that contain control variables and fixed individual and year effects and are estimated using a quadratic polynomial of age which is fully interacted with a dummy variable indicating an age greater than or equal to the MLTPA. Therefore, our robustness checks show that although certain parametric RD models show a significant relationship between the MLTPA and smoking behavior among youth, relatively more flexible parametric RD models and non-parametric RD models document that this relationship is not statistically significant. ${ }^{19}$

\subsection{Alternative samples}

The effect of the MLTPA on smoking behavior might be different in states that enforce alternative MLTPAs. In the first two specifications of Table 5, we investigate the effect of the MLTPA on smoking behavior among young adults who are subject to different MLTPAs such as 18 and 19. ${ }^{20}$ In order to create a subsample of youths who are subject to a MLTPA of 18, we drop the respondents who reside in Alabama, Alaska, and Utah and those who reside in Pennsylvania and were interviewed

\footnotetext{
${ }^{19}$ Although not reported, we also estimate more flexible parametric models, i.e., models that contain cubic and quartic polynomial of age. In these models, the effect of the MLTPA on smoking outcomes remains to be insignificant. These results are available from the authors upon request.

${ }^{20}$ We do not report the effect of the MLTPA of 21 on smoking outcomes for two main reasons. First, at age 21, young adults also gain legal access to alcohol, which may affect smoking participation and confound our analysis. Second, in our sample, the number of young adults who are subject to a MLTPA of 21, i.e., those who reside in Pennsylvania and were interviewed before July 10, 2002, is 204. Due to the small sample size, the results from the RD regressions may not yield credible estimates.
} 
before July 10, 2002 from the full sample. Similarly, in order to create a subsample of youths who are subject to a MLTPA of 19, we only use data from the respondents who reside in Alabama, Alaska, and Utah at the time of the interview. The coefficients from the parametric models that contain full set of controls and are estimated using a quadratic spline and interaction terms imply that the MLTPA of 18 is associated with a 1.5 percentage point increase in the probability of smoking, a 6.7 percent increase in the number of days that young adults smoke cigarettes per month, a 5.5 percent increase in the number of cigarettes smoked on the days that they actually smoked cigarettes, and a 5.7 percent increase in the average number of cigarettes smoked per day. These estimates are slightly smaller than but quite similar to the results from the full sample and remain to be statistically insignificant. Similarly, The MLTPA of 19 is not a significant determinant of smoking behavior among youth. However, these estimates should be interpreted with caution since RD estimates may not yield credible estimates of the effect of the MLTPA of 19 due to the small sample size.

Young adults who have never smoked until the MLTPA are unlikely to change their smoking behavior once they are granted legal access to tobacco products. However, MLTPA laws may significantly affect the smoking behavior of those who have smoked before. We test this possibility in Table 5. When the sample is restricted to those who smoked at least once since the DLI, the impact of the MLTPA on smoking behavior considerably increases and becomes significant. In particular, for those who have smoked before, the MLTPA is associated with a 5.1 percentage point increase in the probability of smoking in the past month, a 24.7 percent increase in the number of days that they smoke cigarettes per month, and a 9.5 percent increase in the number of cigarettes that they smoke on the days they actually smoke. Table 1 shows that on average, those who smoked at least once since the DLI smoke 16.6 days a month and on the days they actually smoke, they smoke 8.6 cigarettes. Therefore, those who smoked at least once since the DLI tend to increase their smoking days approximately 4.1 days once they gain legal access to tobacco products and smoke on average 0.8 more cigarettes on the days they actually smoke.

The gender differences in smoking behavior are well-documented (Bauer, Göhlmann, and Sinning, 2007). We also investigate whether the impact of the MLTPA on smoking behavior differs by gender. Table 5 shows that although the MLTPA is not a significant determinant of smoking behavior for females, it significantly affects the smoking habits of males. For males, the MLTPA is associated with a 3.1 percentage point increase in the probability of smoking, a 11.9 percent increase in the number 
of cigarettes that they smoke on the days they actually smoke, and a 10.4 percent increase in the average number of cigarettes smoked per day.

Our regressions control for whether the respondent is a student or not. However, the effect of the MLTPA for high school and college students might be different. In order to address this possibility, we estimate separate regressions for high school and college students. Results reported in Table 5 show that for these groups, the effect of the MLTPA on smoking remains insignificant.

\section{Conclusion}

In this paper, we investigate the effect of the MLTPA on smoking behavior among young adults using a confidential version of the NLSY97, which contains information on respondents' state and county of residence, exact date of birth, and exact interview date. This information is unique and enabled us to clearly identify the treatment and control groups. Although there has been a considerable amount of research on the effect of the MLTPA and youth access laws on smoking and smoking related outcomes, existing studies have two major limitations. First, although the decision to adopt a higher MLTPA might be endogenous, most of the existing studies have made use of the changes in the MLTPA laws that occurred in the 1980s and early 1990s at the state level. Second, none of the existing studies investigate the effect of the MLTPA laws on smoking participation and smoking related outcomes at the national level using a RD design.

Using a RD approach, we document that the overall impact of the MLTPA on several indicators of smoking among young adults is minor and statistically insignificant under relatively more flexible parametric and non-parametric model specifications. Furthermore, the effects of alternative MLTPAs such as 18 and 19 on smoking behavior are also insignificant. However, we also show that granting legal access to cigarettes and tobacco products at the MLTPA leads to an increase in several indicators of smoking participation for males and for those who reported to have smoked before. Our estimates suggest that the probability of smoking among these groups tend to increase up to 5 percentage points at the MLTPA. We also find that those who have smoked at least once since the DLI tend to increase the number of days that they smoke per month by 24.7 percent at the MLTPA cutoff. Males and those who have smoked before not only smoke on more days but also smoke more cigarettes at the MLTPA. We document that due to the MLTPA law, males on average smoke up to 11.9 percent more 
cigarettes on the days they actually smoke. Similarly, for those who have smoked before the MLTPA is associated with a 9.5 percent increase in the number of cigarettes smoked.

In general, our results are robust under several alternative model specifications and imply that policies that are designed to restrict youth access to tobacco are only effective in reducing smoking participation among certain groups of young adults. Although our results have important policy implications, they should also be interpreted with caution. By definition, the RD approach used in this paper has a very good internal but limited external validity. Hence, our results hold for those who are around the MLTPA cutoff, but cannot be generalized to whole population of young adults. They also do not allow us to measure the long term effects of the MLTPA laws. Furthermore, although we document the relationship between the MLTPA and smoking, MLTPA laws may also negative spillover effects on other smoking related outcomes such as alcohol consumption, obesity, psychological well-being, and health status. Therefore, further research is needed to investigate the effects of the MLTPA law on other smoking related outcomes. This calls for detailed survey data on smoking and smoking related outcomes for young adults.

\section{References}

[1] Ahmad, S. and J. Billimek, 2007, Limiting youth access to tobacco: Comparing the long-term health impacts of increasing cigarette exercise taxes and raising the legal smoking age to 21 in the United States, Health Policy, 80, 378-391.

[2] Anger, S., M. Kvasnicka, and T. Siedler, 2011, One last puff? Public smoking bans and smoking behavior, Journal of Health Economics, 30, 591-601.

[3] Auld, M.C., 2005, Smoking, drinking, and income, Journal of Human Resources, 40, 505-518.

[4] Bauer, T., S. Göhlmann, and M. Sinning, 2007, Gender differences in smoking behavior, Health Economics, 16, 895-909.

[5] Baum, C.L., 2009, The effects of cigarette taxes on obesity, Health Economics,18, 3-19.

[6] Cameron, A.C. and P.K. Trivedi, 2005, Microeconometrics: Methods and Applications. New York: Cambridge University Press. 
[7] Carpenter, C. and P. J. Cook, 2008, Cigarette taxes and youth smoking: New evidence from national, state, and local youth risk behavior surveys, Journal of Health Economics, 27, 287-299.

[8] Carpenter, C. and C. Dobkin, 2009, The effect of alcohol consumption on mortality: Regression discontinuity evidence from the minimum drinking age, American Economic Journal: Applied Economics, 1, 164-182.

[9] Carpenter, C., S. Postolek, and C. Warman, 2011, Public-place smoking laws and exposure to environmental tobacco smoke (ETS), American Economic Journal: Economic Policy, 3, 35-61.

[10] Chaloupka, F. and M. Grossman, 1996, Price, tobacco control policies, and youth smoking, NBER Working Paper No. 5740.

[11] Chaloupka, F. and R. L. Pacula, 1998, An examination of gender and race differences in youth smoking responsiveness to price and tobacco control policies, NBER Working Paper No. 6541.

[12] Cheng, M.Y., J. Fan, and J.S. Marron, 1997, On automatic boundary correction, Annals of Statistics, 25, 1691-1708.

[13] Courtemanche, C., 2009, Rising cigarette prices and rising obesity: Coincidence or unintended consequence? Journal of Health Economics, 28, 781-797.

[14] DeCicca, P., D. Kenkel, and A. Mathios, 2002, Putting out the fires: Will higher taxes reduce the onset of youth smoking?, Journal of Political Economy, 110, 144-169.

[15] DeCicca, P. and L. McLeod, 2008, Cigarette taxes and older adult smoking: Evidence from recent large tax increases, Journal of Health Economics, 27, 918-929.

[16] DeCicca, P., et al., 2008, Youth smoking, cigarette prices, and anti-smoking sentiment, Health Economics, 17, 733-749.

[17] DiFranza, J.R., J.A. Savageau, K.E. Fletcher, 2009, Enforcement of underage sales laws as a predictor of daily smoking among adolescents - a national study, BMC Public Health, 9: 107.

[18] Goel, R.K. and M.J. Morey, 1995, The interdependence of cigarette and liquor demand, Southern Economic Journal, 62, 441-459. 
[19] Gruber, J. and J. Zinman, 2001, Youth smoking in the United States: Evidence and implications, Risky Behavior Among Youths: An Economic Analysis, Gruber, J. (eds.), University of Chicago Press, Chicago, 69-120.

[20] Gruber, J. and M. Frakes, 2006, Does falling smoking lead to rising obesity?, Journal of Health Economics, 25, 183-187.

[21] Hahn, J., P. Todd, and W. van der Klaauw, 2001, Identification and estimation of treatment effects with a regression-discontinuity design, Econometrica, 69, 201-209.

[22] Hersch, J., 1998, Teen smoking behavior and the regulatory environment, Duke Law Journal, 47, $1143-1170$.

[23] Imbens, G. and T. Lemieux, 2008, Regression discontinuity designs: A guide to practice, Journal of Econometrics, 142, 615-635.

[24] Imbens, G. and K. Kalyanamaran, 2012, Optimal bandwidth choice for the regression discontinuity estimator, forthcoming in Review of Economic Studies.

[25] Lee, D.S. and T. Lemieux, 2009, Regression discontinuity designs in economics, NBER Working Paper No. 02138.

[26] Leigh, J.P. and M.C. Berger, 1989, Effects of smoking and being overweight on current earnings, American Journal of Preventive Medicine, 5, 8-14.

[27] Levine, P.B., T.A. Gustafson, and Ann D. Velenchik, 1997, More bad news for smokers? The effects of cigarette smoking on wages, Industrial and Labor Relations Review, 50, 493-509.

[28] Liu, F., N. Zhang, K.W. Cheng, and H. Wang, 2010, Reduced smoking and rising obesity: Does smoking ban in the workplace matter?, Economics Letters, 108, 249-252.

[29] Malamud, O. and C. Pop-Eleches, 2011, Home computer use and the development of human capital, Quarterly Journal of Economics, 126, 987-1027.

[30] Porter, J., 2003, Estimation in the regression discontinuity model, Unpublished Manuscript, Harvard University, Department of Economics. 
[31] U.S. Department of Health \& Human Services (USDHHS), 2004, Preventing tobacco use among young people: A report of the Surgeon General, Atlanta, GA.

[32] Yan, J., 2011, Does the Minimum Cigarette Purchase Age of 21 Protect Young Mothers from Cigarettes, Help Their Babies?, Working Paper No. 11-17, Department of Economics, Appalachian State University.

[33] Yörük, B.K. and C. Ertan Yörük, 2011, The impact of minimum legal drinking age laws on alcohol consumption, smoking, and marijuana use: Evidence from a regression discontinuity design using exact date of birth, Journal of Health Economics, 30, 740-752.

[34] Yörük, B.K. and C. Ertan Yörük, 2013, The impact of minimum legal drinking age laws on alcohol consumption, smoking, and marijuana use revisited, Journal of Health Economics, 32, 477-479. 
Table 1. Definition of outcome variables and summary statistics

\begin{tabular}{|c|c|c|c|c|c|}
\hline Variable Name & Definition & Full Sample & $\begin{array}{c}\text { Age }< \\
\text { MLTPA }\end{array}$ & $\begin{array}{l}\text { Age }>= \\
\text { MLTPA }\end{array}$ & $\begin{array}{c}\text { Smoked } \\
\text { since the } \\
\text { DLI }\end{array}$ \\
\hline Smoke & $\begin{array}{l}=1 \text { if the respondent smoked in the last } 30 \\
\text { days. }\end{array}$ & $\begin{array}{l}0.354 \\
(0.478) \\
{[26545]}\end{array}$ & $\begin{array}{l}0.309 \\
(0.462) \\
{[11558]}\end{array}$ & $\begin{array}{l}0.388 \\
(0.487) \\
{[14987]}\end{array}$ & $\begin{array}{c}0.818 \\
(0.386) \\
{[10549]}\end{array}$ \\
\hline Smoking days & $\begin{array}{l}\text { Number of days that the respondent smoked } \\
\text { in the last } 30 \text { days. }\end{array}$ & $\begin{array}{c}7.190 \\
(12.001) \\
{[26545]}\end{array}$ & $\begin{array}{c}5.887 \\
(11.111) \\
{[11558]}\end{array}$ & $\begin{array}{c}8.160 \\
(12.535) \\
{[14987]}\end{array}$ & $\begin{array}{c}16.616 \\
(13.275) \\
{[10549]}\end{array}$ \\
\hline No. of cigs. & $\begin{array}{l}\text { Number of cigarettes that the respondent } \\
\text { smoked in the last } 30 \text { days on the days she } \\
\text { smoked. }\end{array}$ & $\begin{array}{l}2.921 \\
(6.484) \\
{[26549]}\end{array}$ & $\begin{array}{l}2.268 \\
(5.801) \\
{[11556]}\end{array}$ & $\begin{array}{l}3.406 \\
(6.910) \\
{[14993]}\end{array}$ & $\begin{array}{c}8.604 \\
(8.660) \\
{[8202]}\end{array}$ \\
\hline Avg. cigs & $\begin{array}{l}\text { Average number of cigarettes smoked by the } \\
\text { respondent per day in the last } 30 \text { days. }\end{array}$ & $\begin{array}{l}2.629 \\
(6.347) \\
{[26517]}\end{array}$ & $\begin{array}{l}1.990 \\
(5.587) \\
{[11547]}\end{array}$ & $\begin{array}{c}3.105 \\
(6.820) \\
{[14970]}\end{array}$ & $\begin{array}{c}7.763 \\
(8.894) \\
{[8171]}\end{array}$ \\
\hline
\end{tabular}

Notes: Sample weighted means are reported. Standard deviations are reported in parenthesis. Number of observations is reported in brackets. 
Table 2. Test of the smoothness of observable characteristics around the MLTPA

\begin{tabular}{|c|c|c|c|c|c|c|}
\hline & \multicolumn{6}{|c|}{ Outcome } \\
\hline & Student & Income & Black & Hispanic & Female & Employed \\
\hline $\mathrm{T}$ & $\begin{array}{l}-0.017 \\
(0.013)\end{array}$ & $\begin{array}{l}-0.107 \\
(0.118)\end{array}$ & $\begin{array}{c}0.017 \\
(0.013)\end{array}$ & $\begin{array}{c}0.016 \\
(0.013)\end{array}$ & $\begin{array}{c}0.017 \\
(0.014)\end{array}$ & $\begin{array}{c}0.021 \\
(0.017)\end{array}$ \\
\hline $\mathrm{A} \times 100$ & $\begin{array}{c}-0.029 \\
(0.005) * * *\end{array}$ & $\begin{array}{c}0.078 \\
(0.076)\end{array}$ & $\begin{array}{c}0.003 \\
(0.005)\end{array}$ & $\begin{array}{c}0.003 \\
(0.005)^{* *}\end{array}$ & $\begin{array}{c}0.002 \\
(0.006)\end{array}$ & $\begin{array}{c}0.017 \\
(0.007)^{* *}\end{array}$ \\
\hline$A^{2} \times 10000$ & $\begin{array}{c}-0.002 \\
(0.001)^{* * *}\end{array}$ & $\begin{array}{l}-0.006 \\
(0.012)\end{array}$ & $\begin{array}{c}0.001 \\
(0.001)\end{array}$ & $\begin{array}{c}0.001 \\
(0.001)^{* * *}\end{array}$ & $\begin{array}{c}0.001 \\
(0.001)\end{array}$ & $\begin{array}{c}-0.003 \\
(0.001)^{* * *}\end{array}$ \\
\hline $\mathrm{T} \times \mathrm{A} \times 100$ & $\begin{array}{c}-0.082 \\
(0.007) * * *\end{array}$ & $\begin{array}{l}-0.059 \\
(0.083)\end{array}$ & $\begin{array}{l}-0.007 \\
(0.006)\end{array}$ & $\begin{array}{l}-0.007 \\
(0.006)\end{array}$ & $\begin{array}{l}-0.007 \\
(0.007)\end{array}$ & $\begin{array}{l}-0.004 \\
(0.010)\end{array}$ \\
\hline $\mathrm{T} \times \mathrm{A}^{2} \times 10000$ & $\begin{array}{c}0.011 \\
(0.001)^{* * *}\end{array}$ & $\begin{array}{c}0.003 \\
(0.013)\end{array}$ & $\begin{array}{l}-0.000 \\
(0.001)\end{array}$ & $\begin{array}{c}-0.000 \\
(0.001)^{* *}\end{array}$ & $\begin{array}{l}-0.000 \\
(0.001)\end{array}$ & $\begin{array}{c}0.004 \\
(0.001)^{* * *}\end{array}$ \\
\hline Constant & $\begin{array}{c}0.814 \\
(0.009)^{* * *}\end{array}$ & $\begin{array}{c}10.165 \\
(0.096)^{* * *}\end{array}$ & $\begin{array}{c}0.258 \\
(0.009)^{* * *}\end{array}$ & $\begin{array}{c}0.258 \\
(0.009) * * *\end{array}$ & $\begin{array}{c}0.482 \\
(0.011)^{* * *}\end{array}$ & $\begin{array}{c}0.504 \\
(0.012)^{* * *}\end{array}$ \\
\hline No. of obs. & 26738 & 15276 & 26738 & 26738 & 26738 & 26734 \\
\hline $\mathrm{R}^{2}$ & 0.1565 & 0.0027 & 0.0002 & 0.0003 & 0.0002 & 0.0459 \\
\hline
\end{tabular}

Notes: $\mathrm{T}$ is a binary treatment variable which is equal to 1 if the respondent's age is greater than or equal to the MLTPA as of the interview date. For each respondent, A denotes the difference in days between the interview date and the MLTPA that she is subject to. The signs $* *$ and $* * *$ denote the statistical significance at the 5 and 1 percent significance levels, respectively. Robust standard errors clustered at the individual level are reported in parenthesis. 
Table 3. The effect of the MLTPA on smoking

\begin{tabular}{|c|c|c|c|c|c|c|c|c|c|c|c|c|}
\hline & \multicolumn{12}{|c|}{ Outcome } \\
\hline & \multicolumn{3}{|c|}{ Smoke } & \multicolumn{3}{|c|}{ Smoking days } & \multicolumn{3}{|c|}{ No. of cigs. } & \multicolumn{3}{|c|}{ Avg. cigs. } \\
\hline & (1) & $(2)$ & $(3)$ & (4) & $(5)$ & $(6)$ & $(7)$ & $(8)$ & (9) & (10) & (11) & $(12)$ \\
\hline $\mathrm{T}$ & $\begin{array}{c}0.019 \\
(0.015)\end{array}$ & $\begin{array}{c}0.029 \\
(0.016)^{*}\end{array}$ & $\begin{array}{c}0.020 \\
(0.013)\end{array}$ & $\begin{array}{c}0.088 \\
(0.074)\end{array}$ & $\begin{array}{c}0.120 \\
(0.077)\end{array}$ & $\begin{array}{c}0.089 \\
(0.059)\end{array}$ & $\begin{array}{c}0.046 \\
(0.059)\end{array}$ & $\begin{array}{c}0.077 \\
(0.062)\end{array}$ & $\begin{array}{c}0.067 \\
(0.047)\end{array}$ & $\begin{array}{c}0.037 \\
(0.055)\end{array}$ & $\begin{array}{c}0.055 \\
(0.057)\end{array}$ & $\begin{array}{c}0.065 \\
(0.041)\end{array}$ \\
\hline$A \times 100$ & $\begin{array}{c}0.001 \\
(0.006)\end{array}$ & $\begin{array}{l}-0.007 \\
(0.006)\end{array}$ & $\begin{array}{l}-0.009 \\
(0.007)\end{array}$ & $\begin{array}{c}0.025 \\
(0.031)\end{array}$ & $\begin{array}{l}-0.017 \\
(0.031)\end{array}$ & $\begin{array}{l}-0.033 \\
(0.034)\end{array}$ & $\begin{array}{c}0.029 \\
(0.024)\end{array}$ & $\begin{array}{l}-0.004 \\
(0.024)\end{array}$ & $\begin{array}{l}-0.025 \\
(0.026)\end{array}$ & $\begin{array}{c}0.036 \\
(0.022)\end{array}$ & $\begin{array}{c}0.001 \\
(0.022)\end{array}$ & $\begin{array}{l}-0.018 \\
(0.024)\end{array}$ \\
\hline$A^{2} \times 10000$ & $\begin{array}{c}-0.001 \\
(0.001)^{*}\end{array}$ & $\begin{array}{c}-0.002 \\
(0.001)^{* *}\end{array}$ & $\begin{array}{c}-0.001 \\
(0.001)^{*}\end{array}$ & $\begin{array}{c}-0.006 \\
(0.004)\end{array}$ & $\begin{array}{c}-0.009 \\
(0.004)^{* *}\end{array}$ & $\begin{array}{l}-0.005 \\
(0.003)\end{array}$ & $\begin{array}{l}-0.004 \\
(0.003)\end{array}$ & $\begin{array}{c}-0.006 \\
(0.003)^{* *}\end{array}$ & $\begin{array}{c}-0.004 \\
(0.003)\end{array}$ & $\begin{array}{l}-0.003 \\
(0.003)\end{array}$ & $\begin{array}{c}-0.005 \\
(0.003)^{*}\end{array}$ & $\begin{array}{l}-0.004 \\
(0.002)\end{array}$ \\
\hline $\mathrm{T} \times \mathrm{A} \times 100$ & $\begin{array}{c}0.016 \\
(0.008)^{*}\end{array}$ & $\begin{array}{l}-0.004 \\
(0.009)\end{array}$ & $\begin{array}{c}0.010 \\
(0.008)\end{array}$ & $\begin{array}{c}0.064 \\
(0.039)\end{array}$ & $\begin{array}{l}-0.037 \\
(0.042)\end{array}$ & $\begin{array}{c}0.034 \\
(0.035)\end{array}$ & $\begin{array}{c}0.051 \\
(0.031)^{*}\end{array}$ & $\begin{array}{l}-0.037 \\
(0.033)\end{array}$ & $\begin{array}{c}0.022 \\
(0.027)\end{array}$ & $\begin{array}{c}0.041 \\
(0.028)\end{array}$ & $\begin{array}{l}-0.040 \\
(0.030)\end{array}$ & $\begin{array}{c}0.013 \\
(0.024)\end{array}$ \\
\hline $\mathrm{T} \times \mathrm{A}^{2} \times 10000$ & $\begin{array}{c}0.000 \\
(0.001)\end{array}$ & $\begin{array}{c}0.003 \\
(0.001)^{* *}\end{array}$ & $\begin{array}{c}0.000 \\
(0.001)\end{array}$ & $\begin{array}{l}-0.003 \\
(0.006)\end{array}$ & $\begin{array}{c}0.012 \\
(0.006)^{* *}\end{array}$ & $\begin{array}{c}0.001 \\
(0.005)\end{array}$ & $\begin{array}{l}-0.004 \\
(0.005)\end{array}$ & $\begin{array}{c}0.009 \\
(0.005)^{* *}\end{array}$ & $\begin{array}{c}0.001 \\
(0.004)\end{array}$ & $\begin{array}{l}-0.005 \\
(0.004)\end{array}$ & $\begin{array}{c}0.008 \\
(0.004)^{*}\end{array}$ & $\begin{array}{c}0.001 \\
(0.003)\end{array}$ \\
\hline Constant & $\begin{array}{c}0.305 \\
(0.011)^{* * *}\end{array}$ & $\begin{array}{c}0.550 \\
(0.022)^{* * *}\end{array}$ & $\begin{array}{c}0.264 \\
(0.039)^{* * *}\end{array}$ & $\begin{array}{c}-0.809 \\
(0.054)^{* * *}\end{array}$ & $\begin{array}{c}0.613 \\
(0.114)^{* * *}\end{array}$ & $\begin{array}{c}-1.039 \\
(0.182)^{* * *}\end{array}$ & $\begin{array}{c}-1.145 \\
(0.043)^{* * *}\end{array}$ & $\begin{array}{c}0.163 \\
(0.098)^{*}\end{array}$ & $\begin{array}{c}-1.378 \\
(0.140)^{* * *}\end{array}$ & $\begin{array}{c}-1.324 \\
(0.040)^{* * *}\end{array}$ & $\begin{array}{l}-0.131 \\
(0.088)\end{array}$ & $\begin{array}{c}-1.530 \\
(0.132)^{* * *}\end{array}$ \\
\hline Controls & No & Yes & Yes & No & Yes & Yes & No & Yes & Yes & No & Yes & Yes \\
\hline Ind. fixed effects & No & No & Yes & No & No & Yes & No & No & Yes & No & No & Yes \\
\hline No. of obs. & 26545 & 26545 & 26545 & 26545 & 26545 & 26545 & 26549 & 26549 & 26549 & 26517 & 26517 & 26517 \\
\hline $\mathrm{R}^{2}$ & 0.008 & 0.074 & 0.024 & 0.010 & 0.095 & 0.036 & 0.012 & 0.107 & 0.041 & 0.012 & 0.112 & 0.047 \\
\hline
\end{tabular}

Notes: Log transformed outcomes are used as dependent variables except for the first outcome. $\mathrm{T}$ is a binary treatment variable which is equal to 1 if the respondent's age is greater than or equal to the MLTPA as of the interview date. For each respondent, A denotes the difference in days between the interview date and the MLTPA that she is subject to. Regressions that include control variables also include survey year fixed effects. The control variables are discussed in the text. The signs $*, * *$, and $* * *$ denote the statistical significance at the 10, 5 and 1 percent significance levels, respectively. Robust standard errors clustered at the individual level are reported in parenthesis. 
Table 4. The effect of the MLTPA on smoking: Robustness checks

\begin{tabular}{lcccc}
\hline & \multicolumn{3}{c}{ Outcome } \\
\cline { 2 - 4 } & Smoke & Smoking days & No. of cigs. & Avg. cigs. \\
\hline Alternative parametric models: & & & & \\
Linear without interactions & 0.017 & 0.090 & 0.062 & 0.062 \\
& $(0.008)^{* *}$ & $(0.034)^{* *}$ & $(0.029)^{* *}$ & $(0.026)^{* *}$ \\
Linear with interactions & 0.017 & 0.089 & 0.062 & 0.062 \\
& $(0.008)^{* *}$ & $(0.037)^{* *}$ & $(0.029)^{* *}$ & $(0.026)^{* *}$ \\
Quadratic without interactions & 0.016 & 0.085 & 0.059 & 0.058 \\
Quadratic with interactions & $(0.008)^{* *}$ & $(0.037)^{* *}$ & $(0.029)^{* *}$ & $(0.026)^{* *}$ \\
No. of. obs. & 0.020 & 0.089 & 0.067 & 0.065 \\
Non-parametric model & $(0.013)$ & $(0.059)$ & $(0.047)$ & $(0.041)$ \\
& 26545 & 26545 & 26549 & 26517 \\
\hline
\end{tabular}

Notes: Log transformed outcomes are used as dependent variables in the last three columns. All parametric regressions include individual and year fixed effects and time variant control variables as discussed in the text. For parametric models, robust standard errors clustered at the individual level are reported in parenthesis. For non-parametric models, standard errors are calculated using 1000 bootstrap replications and are reported in parenthesis. Optimal bandwidths are reported in brackets. Optimal bandwidth selection procedure is discussed in the text. The sign ** denotes the statistical significance at the 5 percent significance level. 
Table 5. The effect of the MLTPA on smoking: Alternative samples

\begin{tabular}{lcccc}
\hline & \multicolumn{4}{c}{ Outcome } \\
\cline { 2 - 5 } & Smoke & Smoking days & No. of cigs. & Avg. cigs. \\
\hline Alternative MLTPAs: & & & & \\
MLTPA of 18 & 0.015 & 0.067 & 0.055 & 0.057 \\
& $(0.016)$ & $(0.061)$ & $(0.048)$ & $(0.042)$ \\
& {$[25274]$} & {$[25274]$} & {$[25276]$} & {$[25247]$} \\
MLTPA of 19 & 0.049 & 0.218 & 0.017 & -0.041 \\
& $(0.067)$ & $(0.295)$ & $(0.224)$ & $(0.192)$ \\
Alternative samples: & {$[844]$} & {$[844]$} & {$[845]$} & {$[843]$} \\
Smoked since the DLI & & & & \\
& 0.051 & 0.247 & 0.095 & 0.162 \\
Male & $(0.025)^{* *}$ & $(0.118)^{* *}$ & $(0.057)^{*}$ & $(0.101)$ \\
& {$[10549]$} & {$[10549]$} & {$[8202]$} & {$[8171]$} \\
Female & 0.031 & 0.137 & 0.119 & 0.104 \\
& $(0.019)^{*}$ & $(0.085)$ & $(0.068)^{*}$ & $(0.061)^{*}$ \\
High school student & {$[13670]$} & {$[13670]$} & {$[13662]$} & {$[13655]$} \\
& 0.011 & 0.053 & 0.029 & 0.034 \\
& $(0.018$ & $(0.081)$ & $(0.063)$ & $(0.055)$ \\
& {$[12875]$} & {$[12875]$} & {$[12887]$} & {$[12863]$} \\
& -0.005 & -0.047 & -0.030 & -0.057 \\
& $(0.022)$ & $(0.097)$ & $(0.077)$ & $(0.067)$ \\
& {$[13248]$} & {$[13248]$} & {$[13248]$} & {$[13239]$} \\
& 0.071 & 0.077 & -0.023 & -0.171 \\
& $(0.061)$ & $(0.239)$ & $(0.208)$ & $(0.185)$ \\
& {$[5345]$} & {$[5345]$} & {$[5346]$} & {$[5340]$} \\
\hline
\end{tabular}

Notes: Log transformed outcomes are used as dependent variables in the last three columns. All regressions are estimated using a parametric model that contains a quadratic polynomial of age, which is fully interacted with the treatment variable. All regressions also include individual and year fixed effects and time variant control variables as discussed in the text. The signs $*$ and ** denote the statistical significance at the 10 and 5 percent significance levels, respectively. Robust standard errors clustered at the individual level are reported in parenthesis. Number of observations is reported in brackets. 
Figure 1. Trends in selected observable covariates before and after the MLTPA

A. Student

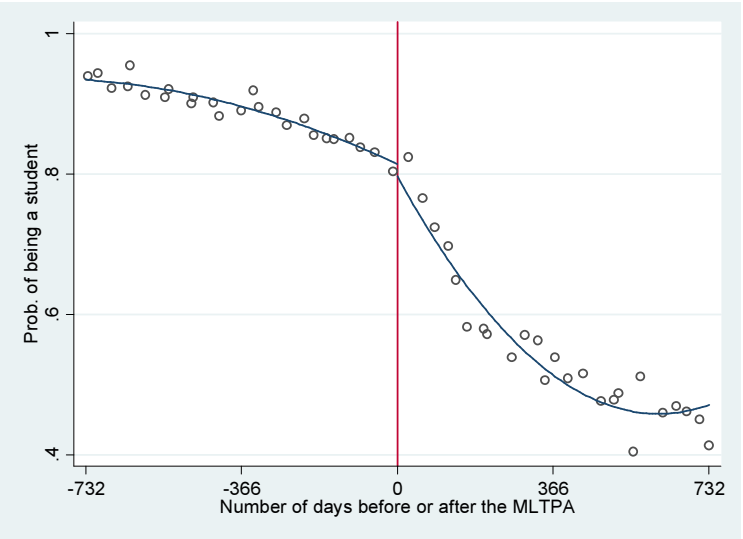

C. Black

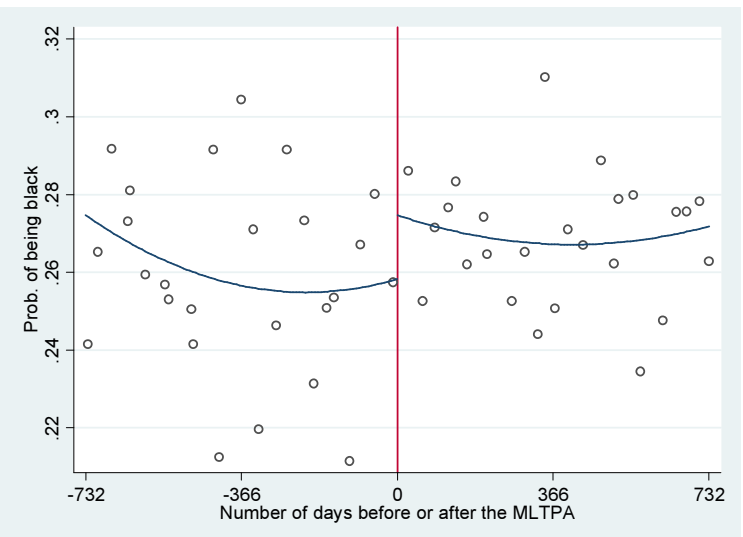

E. Female

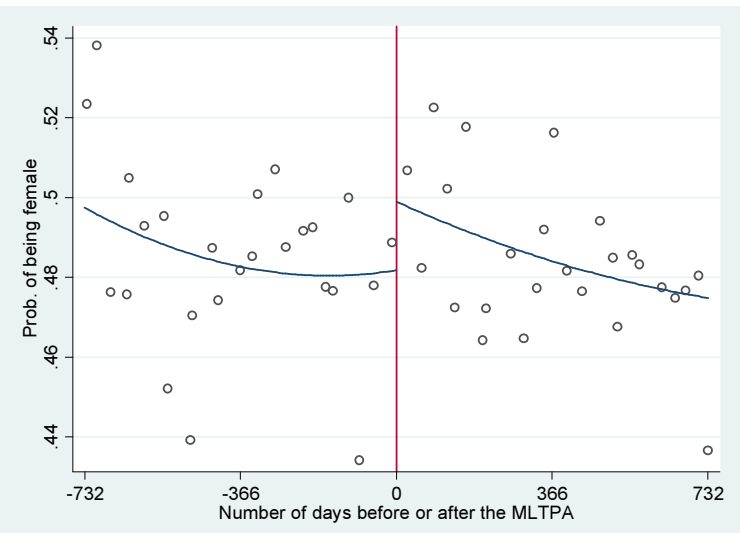

B. $\ln ($ Income $)$

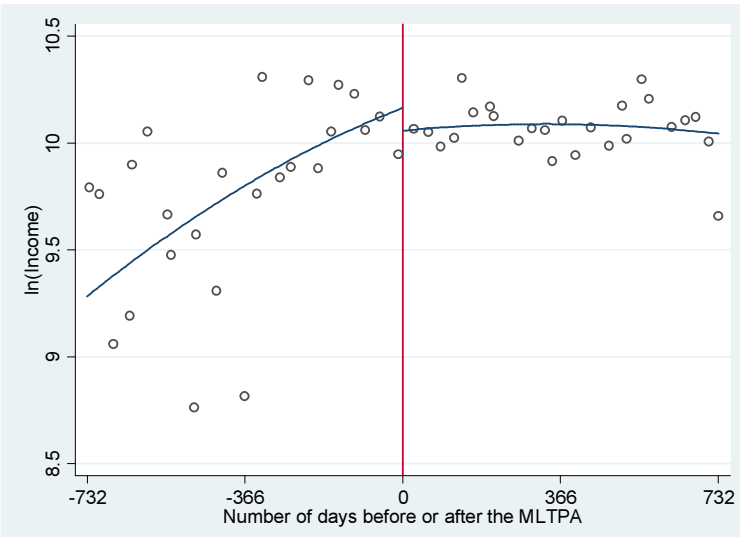

D. Hispanic

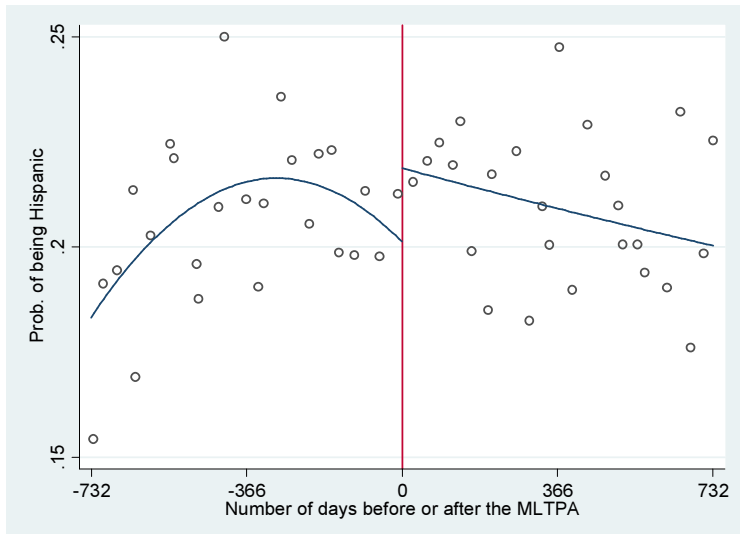

F. Employed

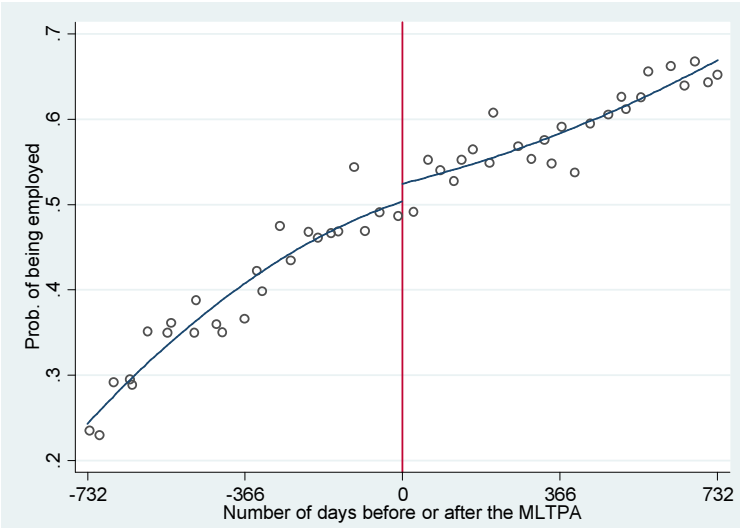

Notes: Mean of the observable covariates for 30 day intervals are plotted. The solid lines are a second-order polynomial fitted on individual observations on either side of the MLTPA as reported in Table 2. 
Figure 2. Predicted smoking trends before and after the MLTPA

A. Smoke

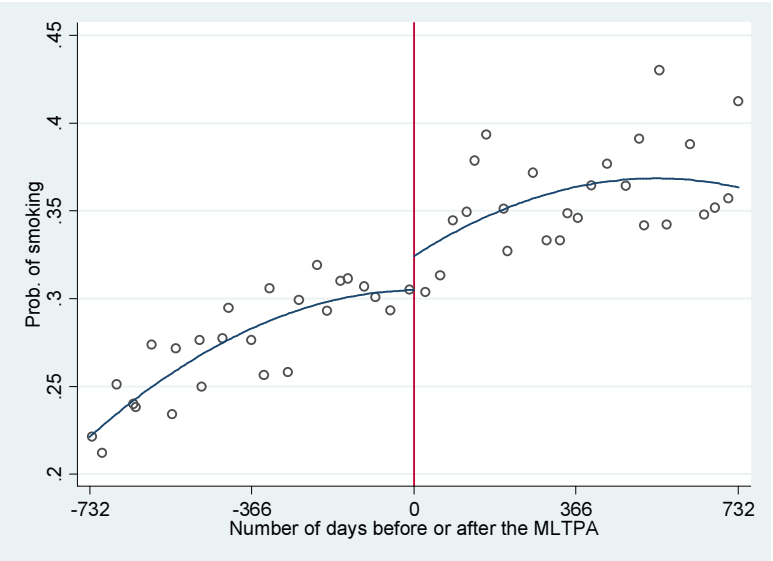

C. No. of cigs.

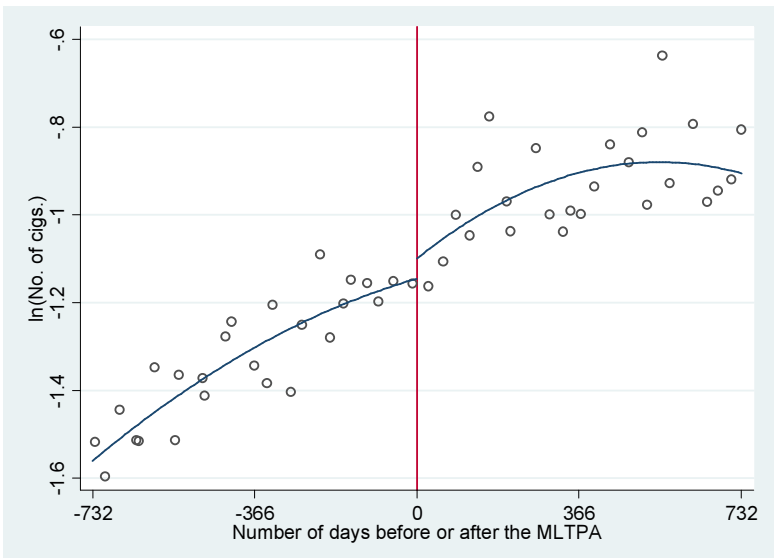

B. Smoking days

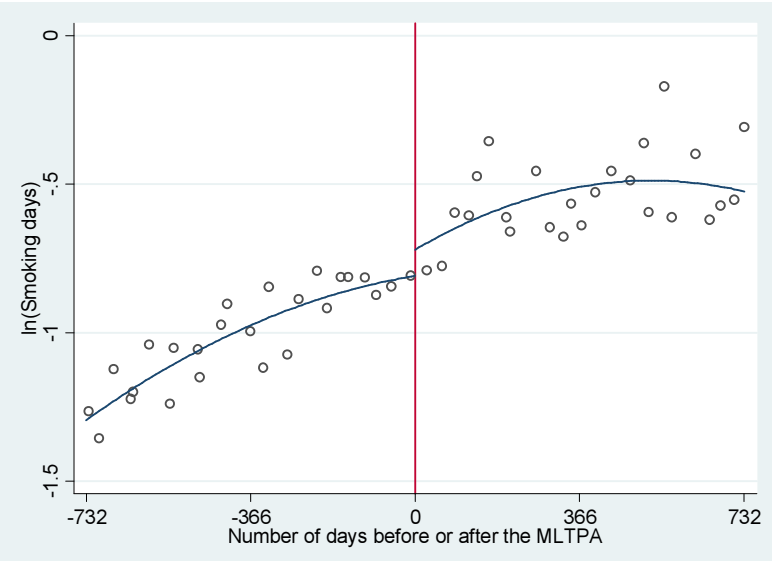

D. Avg. cigs.

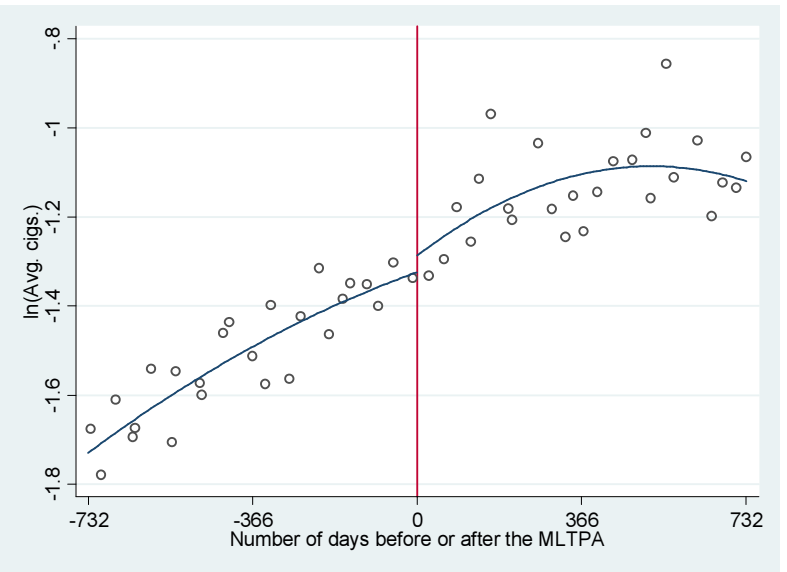

Notes: Means of the outcome variables for 30 day intervals are plotted. The solid lines are a second-order polynomial fitted on individual observations on either side of the MLTPA cutoff without any control variables as reported in specifications $1,4,7$, and 10 of Table 3 . 